\title{
Editorial
}

\section{Fruit and vegetable consumption revisited}

The consumption of fruit and vegetables is still not approaching satisfactory levels in most studied populations. Despite endless efforts to promote intake among children, adolescents and adults, intake of these products still falls short of recommendations. What are we doing wrong?

This issue of Public Health Nutrition focuses on fruit and vegetable consumption. We have gathered a number of papers dealing with policy aspects, access to farmers' markets, parenting styles and interventions in different settings, as well as changes in consumption over time in rapidly changing societies ${ }^{(1-10)}$.

Being able to identify so many papers on this particular topic among our submissions tells us that there are many initiatives focusing on this food group. It also tells us that there is a lot of interest in identifying eating patterns, in improving eating patterns in relation to fruit and vegetable consumption all over the world, and in relating these patterns to sociodemographic characteristics as well as to parenting styles. We certainly have good reasons to turn our attention to this area of public health nutrition research, and we look forward to following developments in this regard.

Agneta Yngve Deputy Editor

Email: agneta.yngve@oru.se

\section{References}

1. Mak TN, Prynne CJ, Cole D et al. (2013) Patterns of sociodemographic and food practice characteristics in relation to fruit and vegetable consumption in children: results from the UK National Diet and Nutrition Survey
Rolling Programme (2008-2010). Public Health Nutr 16 , 1912-1923.

2. Krull S, Stickley A, Roberts B et al. (2013) Changing patterns of fruit and vegetable intake in countries of the former Soviet Union. Public Health Nutr 16, 1924-1932.

3. Olsho LEW \& Fernandes MM (2013) Relationship of white potato to other vegetable consumption by schoolchildren and adolescents in the USA: National Health and Nutrition Examination Survey, 2003-2008. Public Health Nutr 16, 1933-1936.

4. Lin B-H, Wendt M \& Guthrie JF (2013) Impact on energy, sodium and dietary fibre intakes of vegetables prepared at home and away from home in the USA. Public Health Nutr 16, 1937-1943.

5. Jilcott Pitts SB, Wu Q, McGuirt JT et al. (2013) Associations between access to farmers' markets and supermarkets, shopping patterns, fruit and vegetable consumption and health indicators among women of reproductive age in eastern North Carolina, USA. Public Health Nutr 16, 1944-1952.

6. Ayala GX, Baquero B, Laraia BA et al. (2013) Efficacy of a store-based environmental change intervention compared with a delayed treatment control condition on store customers' intake of fruits and vegetables. Public Health Nutr 16, 1953-1960.

7. Glasson C, Chapman K, Wilson T et al. (2013) Increased exposure to community-based education and below the line' social marketing results in increased fruit and vegetable consumption. Public Health Nutr 16, 1961-1970.

8. Middlestadt SE, Lederer AM, Smith NK et al. (2013) Determinants of middle-school students asking parents for fruits and vegetables: a theory-based salient belief elicitation. Public Health Nutr 16, 1971-1978.

9. Peters J, Dollman J, Petkov J et al. (2013) Associations between parenting styles and nutrition knowledge and 2-5-year-old children's fruit, vegetable and non-core food consumption. Public Health Nutr 16, 1979-1987.

10. Wansink B, Shimizu M \& Brumberg A (2013) How vegetables make the meal: their hedonic and heroic impact on perceptions of the meal and of the preparer. Public Health Nutr 16, 1988-1994. 